\title{
Development of semiochemical-based strategies for old-house borer, Hylotrupes bajulus (Coleoptera: Cerambycidae)
}

\begin{abstract}
Earlier studies have demonstrated that among the eight differently colored ground traps tested in the greenhouse, black colored traps were the most effective compared with the performances of brown, yellow, red, grey, blue, white, and green traps. In the present study, efficiency of ground traps with different shades of black (black thick, pure black, mix black and black medium) were evaluated in the greenhouse for the capture of Hylotrupes bajulus. Black thick colored traps caught significantly higher $H$. bajulus than traps with other shades of black. Therefore, black thick colored ground traps are recommended to use for monitoring and mass trapping $H$. bajulus in museums and human dwellings.
\end{abstract}

Key words: color cues, semiochemicals, Hylotrupes bajulus, traps, Cerambycidae.

\section{INTRODUCTION}

The old-house borer beetle (Hylotrupes bajulus) is a major cause of damage to softwood timbers including in the buildings with cultural heritage importance (Becker, 1979). This borer is a native of northern Africa, but is now widespread, with a range which includes Europe, North and South America, South Africa, Asia Minor, China and Russia (Durr, 1954; Duffy, 1963).

Insecticides must have good penetration characteristics to control this wood borer because larvae of $H$. bajulus feed below the surface of wood. However, the application of insecticides is detrimental and frequently undesirable, particularly in the human dwellings and cultural properties. In this context, the development semiochemicalbased trapping method could provide an alternative control measure, as well as providing a mechanism for monitoring populations of this insect (Reddy \& Guerrero, 2004; 2010). To improve the surveillance capability, much research has been done to test the attractiveness of sex pheromones and monoterpenoids within the laboratory or similar enclosed conditions. Our previous studies indicated that a 'ground trap' baited with synthetic sex pheromone (3R)-ketol + 1-butanol was the most efficient trap in capturing H. bajulus in both greenhouse and field tests (Reddy et al., 2005a; 2005b).

Additionally, our previous studies indicate a ground trap baited with a pheromone+ethyl acetate blend can efficiently trap adult $H$. bajulus (Reddy, 2007). 
Importantly, trap color was a significant factor in trap efficacy. Moreover, $H$. bajulus preferred black color over other colors. In this current study, the response H. bajulus to different shades of black colors was investigated in the greenhouse.

\section{MATERIALS AND METHODS}

Hylotrupes bajulus larvae are reared in darkness at $25^{\circ} \mathrm{C}$ and $75 \%$ R.H. at the Institute of Wood Biology and Wood Protection, Hamburg, Germany as described previously (Fettköther et al., 2000). Pheromone dispensers and ground trap used in this study were the same as in our previous study (Reddy et al., 2005a; 2005b; Reddy, 2007). Experiments were conducted between 1200 and $1730 \mathrm{~h}$, a period in which most beetles produce and respond to pheromones (Fettköther et al., 2000). All experiments were conducted in a greenhouse using a screen cage $(450 \mathrm{~cm}$ long x $230 \mathrm{~cm}$ wide x 100 $\mathrm{cm}$ high) with six openings to insert or remove both traps and beetles.

Trap-color characteristics were determined using a Konica Minolta CR-410 Chromometer (Minolta Instrument Systems, Ramsey, NJ). L* which indicates a measure of 'lightness' that runs through the median of the color-scale chart, where 100 (at the top) represents white, and zero (at the bottom) represents black. The a* axis, which runs from left to right on the color chart, indicates a red shade when greater than zero (positive) and a green shade when lower than zero (negative). Similarly, the $b^{*}$ axis which runs vertically through the color chart indicates a yellow shade when positive and a blue shade when negative. The hue angle is expressed on a $360^{\circ}$ grid on which $0^{\circ}$ $=$ red, $90^{\circ}=$ yellow, $180^{\circ}=$ green, and $270^{\circ}=$ blue $($ Wrolstad et al., 2005). Trap color measurement values are given in Tab. 1 .

\begin{tabular}{|c|c|c|c|c|c|}
\hline Trap Color & L* & $\mathbf{a}^{*}$ & $\mathbf{b}^{*}$ & Chroma & $\begin{array}{c}\text { Hue } \\
\text { angle } \\
\left(\mathbf{h}^{\circ}\right)\end{array}$ \\
\hline Pure black & $32.75 \pm 0.24$ & $-0.18 \pm 0.03$ & $0.72 \pm 0.03$ & $0.74 \pm 0.02$ & --- \\
\hline Mix black & $31.89 \pm 0.03$ & $-0.12 \pm 0.02$ & $0.95 \pm 0.02$ & $0.96 \pm 0.02$ & --- \\
\hline Black medium & $30.44 \pm 0.06$ & $0.42 \pm 0.03$ & $-1.08 \pm 0.04$ & $1.16 \pm 0.05$ & --- \\
\hline Black thick & $33.8 \pm 0.1$ & $7.6 \pm 0.2$ & $-5.4 \pm 0.1$ & $9.28 \pm 0.1$ & --- \\
\hline
\end{tabular}

Tab. 1 - Colour measurements of the different shades of black. Means $( \pm \mathrm{SD})$ were generated from three observations.

$\mathrm{L}^{*}$ indicates a measure of 'lightness' that runs through the centre of the colour chart, where 100 at the top represents white and zero at the bottom represents black. The a* axis, which runs left to right on the colour chart, indicates a red shade when greater than zero (positive) and a green shade when lower than zero (negative). Similarly, the $b^{*}$ axis which runs vertically through the colour chart indicates a yellow shade when positive and a blue shade when negative. 
The ground trap with different shades of black (pure black, mix black, black medium and black thick) colors were tested individually (eight replicates, 40 insects per color). The trap tested was placed on the floor of the screen cage $2 \mathrm{~h}$ before the release of the adults, so that pheromone vapors could spread throughout the laboratory. Forty adults were then released into the laboratory, about $3 \mathrm{~m}$ from the trap. The number of adults trapped during the succeeding $3 \mathrm{~h}$ was recorded. Trapped beetles were removed after capture and discarded. Uncaptured insects were removed before the next trial, and we used fresh adults for each replicate to avoid pseudoreplication.

The data was analyzed with the generalized linear mixed model procedure of SAS Version 9.13 (SAS Institute 2009). Because all the response variables used in the experiments were counts, a one-way Poisson ANOVA model was fitted by The GLIMMIX Procedure to analyze the data from the experiments. For the comparisons of the means, the least square means test was used to make multiple comparisons for significant differences between treatments at $\mathrm{P}=0.05$.

\section{RESULTS}

The shade of black significantly affected adult catches in ground traps $(\mathrm{F}=8.2$; $\mathrm{df}=3,22 ; \mathrm{P}<0.05$; Fig. 1). Black thick colored traps caught significantly more adult weevils $(20.0 \pm 0.8$ adults/trap) than did other shades. Pure black, mix black and black medium colored traps did not differ significantly in the numbers caught, as they caught $8.0 \pm 1.2,7.0 \pm 0.9,8.0 \pm 06$ adults/trap, respectively).

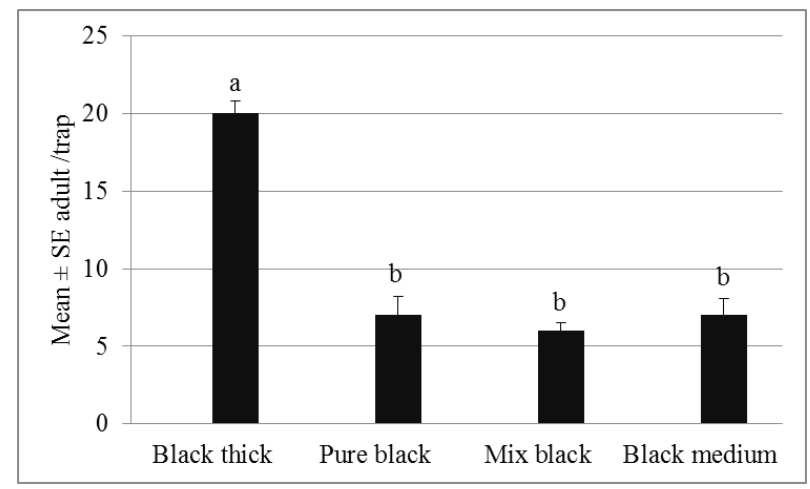

Fig. 1 - Mean ( \pm SE) numbers of adult $H$. bajulus caught in semiochemical-baited ground traps of different shades of black in a greenhouse. Different lower-case letters indicate significant differences between treatments (one-way ANOVA using Poisson model, least square means, $\mathrm{P}<0.01)$. Adding black to the other colors did not improve their performance. Bars represent means of four replicates. 


\section{DISCUSSION AND CONCLUSIONS}

Our previous studies have confirmed that among the eight differently colored traps tested in the greenhouse, black traps were the most effective compared with the performances of yellow, red, grey, blue, brown, white, and green traps (Reddy, 2007). In the present color-choice tests study, effectiveness of ground trap with the different shades of black was evaluated in the greenhouse for the capture of $H$. bajulus. The results indicated, $H$. bajulus preferred black thick over other color traps, with no specific preferences for different other shades of black. Although previous studies by Reddy \& Raman (2011) and Reddy et al. (2011) reported that the black colored traps were preferred by Cosmopolites sordidus (Germar) (Coleoptera: Curculionidae) and Rhabdoscelus obscurus (Boisduval) (Coleoptera: Curculionidae) indoor conditions, no significant difference occurred in trials made comparing between the different shades of black traps in capturing the adults. By exploiting these results, it may be possible to produce efficacious trapping systems that could be used in a behavioral approach to old-house borer control. Black thick colored traps used in this study could be effectively installed for the monitoring and mass trapping of $H$. bajulus particularly in museums and human dwellings.

\section{ACKNOWLEDGMENTS}

The research was funded by the German Federal Foundation for the Environment (Deutsche Bundesstiftung Umwelt, Osnabrück). The author thanks the Alexander von Humboldt Foundation for the Humboldt Research Fellowship and an anonymous reviewer for his comments and suggestions.

\section{REFERENCES}

Becker H., 1979 - Die Verbreitung des Hausbockkäfers Hylotrupes bajulus (L.) Serville (Col., Cerambycidae). Prakt Schädlingsbekämpfer, 31:3-19.

DurR H.J.R., 1954 - The European House Borer Hylotrupes bajulus (L.) (Coleoptera: Cerambycidae) and its Control in the Western Cape Province. Department of Agriculture, South Africa.

DufFy E.A.J., 1963 - A Monograph of the Immature Stages of Australasian Timber Beetles (Cerambycidae). British Museum (Natural History), London.

Fettköther R., Reddy G.V.P., Noldt U., Dettner K., 2000 - Effect of host and larval frass volatiles on behavioural response of the old house borer Hylotrupes bajulus (L.) (Coleoptera: Cerambycidae), in a wind tunnel bioassay. Chemoecology, 10: 1-10.

REDDY G.V.P., 2007 - Improved semiochemical-based trapping method for old-house borer, $\mathrm{Hy}$ lotrupes bajulus (Coleoptera: Cerambycidae). Environ. Entomol., 36: 281-286.

Reddy G.V.P., FettKöther R., Noldt U., Dettner K., 2005a - Capture of female Hylotrupes bajulus as influenced by trap type and pheromone blend. J. Chem. Ecol., 31: 2169-2177.

Reddy G.V.P., FetTKÖther R., Noldt U., DetTNER K., 2005b - Enhancement of attraction and trap catches of the old-house borer, Hylotrupes bajulus (Coleoptera: Cerambycidae), by combination of male sex pheromone and monoterpenes. Pest Manag. Sci., 61: 699-704. 
REDDY G.V.P., GUERRERO A., 2004 - Interactions of insect pheromones and plant semiochemicals. Trends in Plant Science, 9: 253-261.

Reddy G.V.P., Guerrero A., 2010 - New pheromones and insect control strategies. Vitam. Horm., 83: 493-519.

Reddy G.V.P., Balakrishnan S., Remolona Je., Kikuchi R., Bamba J.P., 2011 - Influence of trap type, size, color, and trapping location on the capture of the New Guinea sugarcane weevil, Rhabdoscelus obscurus (Coleoptera: Curculionidae). Annal of the Entomological Society of America, 104: in press.

REDDY G.V.P., RAMAN A., 2011- Visual cues are relevant in behavioral control measures for Cosmopolites sordidus (Coleoptera: Curculionidae). Journal of Economic Entomology 104: 436-442.

SAS Institute, 2009 - SAS/STAT 9.3 User's Guide, SAS Institute Inc., Cary, NC, USA.

Wrolstad R.E., Durst R.W., Lee J., 2005 - Tracking color and pigment changes in anthocyanin products. Trends in Food Science \& Technology, 16: 423-428.

GADI V.P. REDDY, Institute of Animal Ecology-II, University of Bayreuth, Postbox 101251, D-95440, Bayreuth, Germany. Present address: Western Pacific Tropical Research Center, University of Guam, Mangilao, Guam 96923, USA.

E-mail: reddy@uguam.uog.edu 